\title{
Glutamine Measurement
}

National Cancer Institute

\section{Source}

National Cancer Institute. Glutamine Measurement. NCI Thesaurus. Code C122121.

The determination of the amount of glutamine present in a sample. 